Fetal Diagnosis

and Therapy
Fetal Diagn Ther 2008;23:245-248

DOI: $\underline{10.1159 / 000116749}$
Received: July 3, 2006

Accepted after revision: December 27, 2006

Published online: February 20, 2008

\title{
Organic Acid Concentrations in Amniotic Fluid Found in Normal and Down Syndrome Pregnancies
}

\author{
Paddy Jim Baggot ${ }^{a, b} \quad$ Anna Jane Y. Eliseo ${ }^{b} \quad$ Nathaniel G. DeNicola ${ }^{b}$ \\ Jeremy A. Kalamarides ${ }^{c}$ James D. Shoemaker ${ }^{d}$

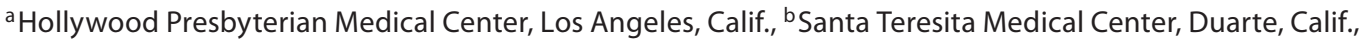 \\ 'Lake Erie College of Osteopathic Medicine, Erie, Pa., and ${ }^{\mathrm{d}}$ Metabolic Screening Laboratory, Saint Louis University \\ School of Medicine, Saint Louis, Mo., USA
}

\section{Key Words}

Amniotic fluid • Down syndrome $\cdot$ Organic acids •

Tetrahydrobiopterin

\begin{abstract}
Introduction: Organic acids were examined from normal and Down syndrome pregnancies to identify possible differences between the amniotic fluid from fetuses with Down Syndrome compared with that of normal fetuses. Materials and Methods: Amniotic fluids were obtained from prior amniocenteses. Forty-one normal and 22 Down syndrome specimens were assayed using gas chromatography/mass spectrometry. Results and Discussion: 5-Hydroxycaproate, methylsuccinate, $\alpha$-ketoglutarate, and adipate were significantly elevated in Down syndrome, suggesting riboflavin deficiency. Phenylpyruvate was also significantly elevated in fetuses with Down syndrome. Phenylpyruvate inhibits the metabolism of tetrahydrobiopterin, which is necessary for neurotransmitter metabolism. Elevated phenylpyruvate is consistent with previous research, suggesting a disturbance of tetrahydrobiopterin metabolism in Down syndrome. Conclusion: Organic acid markers for $\mathrm{B}_{2}$ deficiency are elevated in the amniotic fluid of fetuses with Down syndrome. Eleva-
\end{abstract}

tion of phenylpyruvate may impair neurotransmitter metabolism. Organic acid markers for $\mathrm{B}_{12}$ levels are not different between the Down syndrome and normal group.

Copyright $\odot 2008$ S. Karger AG, Basel

\section{Introduction}

Inborn errors of metabolism involve genetic defects in biochemical metabolism. Many of these disorders cause impairment of mental or neurologic function, e.g. phenylketonuria (PKU). Because some cases of mental retardation are caused by inborn errors, organic acids and amino acids may be studied in children with mental deficiency.

While this technology of inborn errors of metabolism has explained many mechanisms related to childhood neurologic impairment, it has only rarely been used on children with chromosomal disorders, and almost never in fetuses with Down syndrome. In this study, the technology of inborn errors is brought to bear on fetal Down syndrome, so that Down syndrome may be understood not only as a chromosomal problem, but also as a biochemical and metabolic problem.

\section{KARGER}

Fax +4161306 1234 E-Mail karger@karger.ch www.karger.com

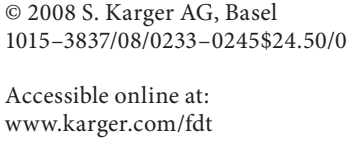

E-Mail pjbaggot@hotmail.com 
Table 1. Organic acid metabolites $(\mu \mathrm{M})$ in Down syndrome and normal amniotic fluid (non-parametric, Mann-Whitney rank sums)

\begin{tabular}{|c|c|c|c|c|c|c|c|c|}
\hline Metabolite & $\begin{array}{l}\text { Down } \\
\text { median }\end{array}$ & $\begin{array}{l}\text { Down } \\
5-95 \% \text { CI }\end{array}$ & $\begin{array}{l}\text { Normal } \\
\text { median }\end{array}$ & $\begin{array}{l}\text { Normal } \\
5-95 \% \text { CI }\end{array}$ & $\mathrm{p}$ & $\begin{array}{l}\text { Biochemical interpretation } \\
\text { [2] }\end{array}$ & $\begin{array}{l}\text { Enzyme } \\
{[3]}\end{array}$ & $\begin{array}{l}\text { Vitamin or } \\
\text { cofactor [3] }\end{array}$ \\
\hline Lactate & $4,681.000$ & $52.000-15,607.500$ & $5,529.500$ & $96.000-17,646.000$ & 0.559 & normally high in amniotic fluid & $\mathrm{LDH}$ & $\mathrm{B}_{1}, \mathrm{~B}_{3}$ \\
\hline$\alpha$-OH-butyrate & 0.750 & $0.00-42.000$ & 15.500 & $0.000-61.000$ & 0.028 & ketosis & & \\
\hline Glycolate & 13.000 & $0.000-214.500$ & 12.000 & $0.000-64.500$ & 0.660 & $\mathrm{~B}_{1}$ & & \\
\hline Glycerate & 26.500 & $0.000-56.500$ & 25.000 & $0.000-60.000$ & 0.943 & $\mathrm{~B}_{2}$ & & \\
\hline 5-hydroxycaproate & 0.100 & $0.000-1.600$ & 0.000 & $0.000-0.550$ & 0.010 & $\mathrm{~B}_{2}$, ETF or CII & CII & $\mathrm{B}_{2}$ \\
\hline Succinate & 1.000 & $0.000-4.000$ & 0.500 & $0.000-4.000$ & 0.371 & $\mathrm{~B}_{2}$, ETF or CII, SCAD & $\mathrm{SDH}$ & $\mathrm{B}_{2}$ \\
\hline Methylsuccinate & 0.175 & $0.000-3.100$ & 0.000 & $0.000-0.350$ & 0.004 & $\mathrm{~B}_{2}$, ETF or CII, SCAD & & \\
\hline Ethylmalonate & 2.525 & $0.000-69.650$ & 5.150 & $0.000-133.700$ & 0.330 & $\mathrm{~B}_{2}$, ETF or CII, SCAD & & \\
\hline Glutarate & 0.100 & $0.000-0.700$ & 0.000 & $0.000-1.000$ & 0.112 & $\mathrm{~B}_{2}$, ETF or CII, glutaric acidemias & CII & $\mathrm{B}_{2}$ \\
\hline$\alpha$-Ketoglutarate & 6.250 & $0.000-45.000$ & 0.000 & $0.000-23.000$ & 0.019 & $\begin{array}{l}\mathrm{B}_{1}, \mathrm{~B}_{2}, \mathrm{~B}_{3} \text { or } \mathrm{B}_{5} \text { deficiency, } \\
\text { mitochondrial }\end{array}$ & AKGDH & $\mathrm{CoA}, \mathrm{B}_{1}, \mathrm{~B}_{3}$ \\
\hline Adipate & 0.050 & $0.000-0.550$ & 0.000 & $0.000-0.300$ & 0.012 & diet, $B_{2}, B_{5}$, fatty acid oxidation & MCAD/CII & $\mathrm{B}_{3}, \mathrm{CoA} / \mathrm{B}_{2}$ \\
\hline Suberate & 0.125 & $0.000-0.750$ & 0.050 & $0.000-0.800$ & 0.147 & diet, $\mathrm{B}_{2}, \mathrm{~B}_{5}$, fatty acid oxidation & MCAD/CII & $\mathrm{B}_{3}, \mathrm{CoA} / \mathrm{B}_{2}$ \\
\hline Sebacate & 0.100 & $0.000-1.950$ & 0.300 & $0.000-2.100$ & 0.168 & diet, $\mathrm{B}_{2}, \mathrm{~B}_{5}$, fatty acid oxidation & MCAD/CII & $\mathrm{B}_{3}, \mathrm{CoA} / \mathrm{B}_{2}$ \\
\hline Fumarate & 0.050 & $0.000-0.450$ & 0.000 & $0.000-0.550$ & 0.186 & mitochondrial, fumaric acidemia & fumarase & \\
\hline Malate & 1.825 & $0.000-7.200$ & 1.000 & $0.000-8.550$ & 0.153 & mitochondrial & $\mathrm{MDH}$ & $\mathrm{B}_{3}$ \\
\hline Octanoate & 0.000 & $0.000-2.500$ & 0.000 & $0.000-2.000$ & 0.834 & fatty acid oxidation, e.g. MCAD & & \\
\hline Hexanoate & 3.750 & $0.000-41.000$ & 6.000 & $0.000-43.000$ & 0.702 & fatty acid oxidation & MCAD/CII & $\mathrm{B}_{3}, \mathrm{CoA} / \mathrm{B}_{2}$ \\
\hline 3-OH-isovalerate & 1.325 & $0.000-8.650$ & 2.350 & $0.000-10.400$ & 0.840 & $\begin{array}{l}\text { biotin, biotinidase or } \\
\text { holocarboxylase }\end{array}$ & 3-MCC & biotin \\
\hline Methylmalonate & 24.900 & $0.000-53.550$ & 21.150 & $0.000-70.750$ & 0.379 & $\mathrm{~B}_{12}$ & mutase & $\mathrm{B}_{12}$ \\
\hline Homogentisate & 0.000 & $0.000-0.250$ & 0.000 & $0.000-0.100$ & 0.515 & alcaptonuria & & \\
\hline 4-OH-butyrate & 0.000 & $0.000-0.500$ & 0.000 & $0.000-0.500$ & 0.265 & GHB & & \\
\hline$\beta$-OH-butyrate & 18.750 & $0.000-151.500$ & 66.000 & $0.000-137.500$ & 0.330 & organic acidemias & & \\
\hline Phenylpyruvate & 0.075 & $0.000-0.550$ & 0.000 & $0.000-0.250$ & 0.045 & PKU & & \\
\hline Succinylacetone & 0.125 & $0.000-0.700$ & 0.050 & $0.000-1.450$ & 0.143 & tyrosinemia (hepatorenal) & & \\
\hline Phosphate & 0.675 & $0.000-2.350$ & 0.650 & $0.000-3.600$ & 0.914 & diet, bone loss, Fanconi syndrome & & \\
\hline Citrate & 25.750 & $2.500-115.000$ & 12.500 & $2.000-125.000$ & 0.371 & present in all samples & & \\
\hline Hippurate & 9.000 & $4.500-31.000$ & 11.000 & $3.500-48.000$ & 0.258 & benzoic acid intake & & \\
\hline Urate & 0.225 & $0.000-0.900$ & 0.200 & $0.000-1.300$ & 0.432 & tissue catabolism & & \\
\hline
\end{tabular}

Figures in bold indicate statistically significant differences $(\mathrm{p}<0.05)$.

$\mathrm{LDH}=$ Lactate dehydrogenase; ETF = electron transfer flavoprotein; CII = complex II of the electron transport chain; SCAD = short chain acyl-CoA dehydrogenase; $\mathrm{SDH}=$ succinate dehydrogenase; $\mathrm{AKGDH}=\alpha$-ketoglutarate dehydrogenase; $\mathrm{MCAD}=$ medium chain acyl-CoA dehydrogenase; $\mathrm{MDH}=$ malate dehydrogenase; 3-MCC = 3-methylcrotonyl carboxylase; GHB $=\gamma$-hydroxybutyrate.

The primary goal of this study was to determine possible biochemical differences in the metabolite profiles of fetuses with Down syndrome. In order to understand the fetal biochemical changes associated with this condition, organic acid analyses were conducted on amniotic fluid from normal fetuses and fetuses with trisomy 21 . This work is part of a larger effort to understand differences in biochemistry between normal and Down syndrome fetuses.

\section{Materials and Methods}

Amniotic fluid specimens were obtained from 41 fetuses which were chromosomally normal and 22 fetuses with Down syndrome. Specimens from fetuses with normal chromosomal complements were used as controls. One specimen having a pericentric inversion of chromosome 9 was maintained in the control group, as this chromosomal finding is considered to be a normal population variant.
The normal samples had been collected between March and April 1996. The group of fetuses having Down syndrome included 24 specimens from May 1993 to October 1995. Controls had a median gestational age of 15.7 weeks and the Down syndrome group had a median gestational age of 16.7 weeks. Amniotic fluid becomes more dilute with advancing gestational age and therefore most metabolites have lower concentrations with advancing gestational age. The difference between 15.7 and 16.7 is small but not zero.

The amniotic fluid specimens were archived and anonymous donor samples were obtained from the Cytogenetic Laboratory at the Medical College of Virginia, Virginia Commonwealth University. The fluid was stored at $-20^{\circ} \mathrm{C}$ at the time of amniocentesis. The cell-free amniotic fluid supernatants were collected following centrifugation of the cells. This is within protocol for collection and shipment of specimens and should not affect results of the study. Frozen specimens from the Medical College of Virginia were then shipped overnight on dry ice to the Metabolic Screening Laboratory at Saint Louis University, Saint Louis, Mo., USA. 
Amniotic Fluid Sample Analysis

Amniotic fluid samples were prepared and analyzed as previously described for urine [1]. After enzymatic removal of urea, organic acid compounds were derivatized, using a trimethylsilyl reagent to prepare the compounds for analysis. The metabolites were then analyzed by gas chromatography/mass spectrometry.

Institutional Review

All samples were archived anonymous specimens from previous amniocenteses, therefore institutional review boards of both the Medical College of Virginia and Saint Louis University waived further review of the experimental protocol.

\section{Statistical Analysis}

SigmaStat ${ }^{\circledR} 3.0$ was used to perform statistical analysis of the data. Tests of normality determined that data for both groups was not normally distributed. Non-parametric evaluation using Mann-Whitney rank sum tests was performed, where $\mathrm{p}<0.05$ was the criterion of statistical significance.

\section{Results and Discussion}

Table 1 contains data in non-parametric form, presenting normal and Down syndrome medians and $\mathrm{p}$ values resulting from Mann-Whitney rank sum tests. 5-Hydroxycaproate, methylsuccinate, $\alpha$-ketoglutarate and adipate are significantly increased in Down syndrome compared with normals. These collective elevations are consistent with riboflavin deficiency, although for individual metabolites, other explanations could apply [2]. Succinate and glutarate are also elevated in Down syndrome, and although the differences are not statistically significant, this trend is consistent with riboflavin deficiency. In summary, there are multiple indicators of riboflavin deficiency.

A statistically significant increase was found in levels of phenylpyruvate between Down syndrome and control specimens. In Down syndrome $(0.075 \mu \mathrm{M})$, the levels of phenylpyruvate were increased compared with normals $(0.0 \mu \mathrm{M})$ and the difference is statistically significant $(\mathrm{p}=0.045)$.

The physiologic significance of phenylpyruvate relates to the metabolism of neurotransmitters. Phenylpyruvate is known to inhibit the biopterin recycling. It inhibits the reduction of dihydrobiopterin to tetrahydrobiopterin [4], which is catalyzed by dihydropteridine reductase (EC 1.6.99.7). This enzyme has been mapped to human chromosome 4p15.1-p16.1 [5]. Tetrahydrobiopterin is necessary for the hydroxylation of phenylalanine, tyrosine and tryptophan.

The relevance of this to neurodevelopment is suggested by experience with biopterin-related PKU. This severe form of PKU involves a dysfunctional enzyme, dihydropteridine reductase, which results in failed biopterin recycling. The disease mechanism responsible for biopterinrelated PKU - which results in mental retardation and multiple defects of neurotransmitter metabolism - could also be involved in mental retardation and CNS abnormalities in Down syndrome. Cattal et al. [6] noted that disturbances of biopterin metabolism have been detected in Down syndrome. Hamon et al. [4] also report that a low level of tetrahydrobiopterin was found in Down syndrome and this was thought to suggest a deficit of dihydrobiopterin reductase activity.

Elevated $\alpha$-OH-butyrate levels are usually characteristic of ketosis. Why this metabolite should be particularly low in the Down syndrome group is unclear to us.

Methylmalonate was quite similar between the normal group $(21.150 \mu \mathrm{M})$ and the Down syndrome group $(24.900 \mu \mathrm{M})$. The $\mathrm{p}$ value for this comparison was 0.379 . These data suggest there is no difference in $\mathrm{B}_{12}$ between normal and Down syndrome groups [7].

\section{Conclusion}

This present work suggests that several markers for riboflavin deficiency are increased in Down syndrome amniotic fluid. Additionally, the data indicate that markers of $B_{12}$ deficiency are no different in the Down syndrome and normal groups, i.e. there is no suggestion of $\mathrm{B}_{12}$ deficiency. Phenylpyruvate is also elevated in the amniotic fluid of fetuses with Down syndrome. The physiologic significance of this finding relates to the metabolism of neurotransmitters and tetrahydrobiopterin, which may be directly involved in the pathogenesis of mental retardation.

Organic acid analysis of amniotic fluid, as presented here, should not replace chromosomal analysis of cultured amniocytes. A fetus with riboflavin deficiency could be misdiagnosed as having Down syndrome. These data may be more useful in helping to understand the physiology and biochemistry of Down syndrome than as a method of prenatal diagnosis.

\section{Acknowledgments}

This work was financially supported by the Michael Fund, of the International Foundation for Genetic Research in Pittsburgh, Pa., USA. Cytogenetic analysis was done at Virginia Commonwealth University in Richmond, Va., USA. Editing assistance was provided by Zelma N. Wasserman. 


\section{References}

-1 Shoemaker JD, Elliott W: Automated screening of urine samples for carbohydrate, organic and amino acids after treatment of urease. J Chromatograph Biomed Appl 1991; 562:125-138.

2 Metabolic screening lab: diagnosing inborn errors of metabolism. Available at http://biochemweb.slu.edu/msl (accessed August 25, 2004).
3 Baggot PJ, Kalamarides JA, Shoemaker JD: Valproate-induced biochemical abnormalities in pregnancy corrected by vitamins: a case report. Epilepsia 1999;40:512-515.

4 Hamon CGB, Blair JA: Tetrahydrobiopterin metabolism in disease; in Lovenberg $\mathrm{W}$, Levine $\mathrm{R}$ (eds): Unconjugated Pterins in Neurobiology. London, Taylor and Francis, 1987, pp 201-213.

5 Yudkoff M: Diseases of amino acid metabolism; in Siegel GJ, Agranoff BW, Albers RW, Fisher SK, Uhler MD (eds): Basic Neurochemistry: Molecular, Cellular and Medical Aspects, ed 6. Philadelphia, Lippincott, Williams and Wilkins, 1999, pp 887-916.
-6 Cattal RJ, Hamon CGB, Korbett JA, Lejeune J, Blaire JA: Neopterin: biopterin ratios in Down syndrome. J Neurol Psychiatry 1989; 52:1015-1016.

7 Fenton WA, Rosenburg LE: Disorders of propionate and methylmalonate metabolism; in Seriver CR, Beaudet AL, Sly WS, Valle D (eds): The Metabolic and Molecular Basis of Inherited Disease, ed 7. New York, McGraw Hill, 1995, pp 1423-1450. 